\title{
THE TAX SYSTEMS OF THE RUSSIAN FEDERATION AND THE UNITED STATES IN THE CONTEXT OF THE PRINCIPLE OF TAX FAIRNESS
}

\author{
Stanislav D. Kazachenkov \\ Rostov State University of Economics (RINH), Rostov-on-Don, Russian Federation
}

Introduction: in order to conduct an effective tax policy in the modern world, the state needs to rethink the development strategy in the field of taxation, which should be based on a system of tax principles, in particular, the principle of tax fairness. The novelty of the study lies in the fact that despite the considerable amount of the theoretical research on the subject, this area is under-researched in the question of the concept of equity in taxation, which is the relevance and need for the study. Purpose: to study the efficiency of the implementation of the principle of fairness in the modern tax system through the example of this country and foreign countries (USA). Methods: the research is based on the comparative method, the method of system analysis and dialectics, synthesis, analogy, deduction, induction, historical method, the method of unity of theory and practice, as well as the special legal methods (the formal legal method, the empirical methods of cognition and the dogmatic methods). Results: the formation of the concept of property taxation based on the principle of equity through the example of Russia and the United States. Conclusions: the principle of fair taxation should take into account the features of the modern legal and social reality, as well as the practical relations in the field of taxation.

Key words: taxation, property taxation, tax system, tax policy, property, principles of taxation, tax fairness, mechanism.

Citation. Kazachenkov S.D. The Tax Systems of the Russian Federation and the United States in the Context of the Principle of Tax Fairness. Legal Concept = Pravovaya paradigma, 2021, vol. 20, no. 1, pp. 56-61. (in Russian). DOI: https://doi.org/10.15688/lc.jvolsu.2021.1.8

УДК 336.226 .2

Дата поступления статьи: 30.12.2020

ББК 67.402

Дата принятия статьи: 28.01.2021

\section{НАЛОГОВЫЕ СИСТЕМЫ РОССИЙСКОЙ ФЕДЕРАЦИИ И США В КОНТЕКСТЕ ПРИНЦИПА СПРАВЕДЛИВОСТИ НАЛОГООБЛОЖЕНИЯ}

\author{
Станислав Дмитриевич Казаченков \\ Ростовский государственный экономический университет (РИНХ), г. Ростов-на-Дону, Российская Федерация
}

Введение: в целях проведения эффективной налоговой политики в современном мире государству необходимо переосмыслить стратегию развития в сфере налогообложения, которая должна опираться на систему принципов налогообложения, в частности принцип справедливости налогообложения. Новизна исследования заключается в том, что, несмотря на значительный объем теоретических исследовательских работ по рассматриваемой тематике, данная область недостаточно исследована в вопросе концепции принципа справедливости в области налогообложения, в чем и проявляется актуальность работы и потребность в изучении. Цель: изучение эффективности реализации принципа справедливости в современной налоговой системе на примере нашей и зарубежной страны (США). Методы: исследование базируется на сравнительном методе, методе системного анализа и диалектики, синтеза, аналогии, дедукции, индукции, историческом методе, методе единства теории и практики, а также специально-юридических методах (формально-юридический метод, эмпирические методы познания и догматические методы). Результаты: формирование концепции имущественного налогообложения на основе принципа справедливости на примере России и США. Выводы: принцип справедливости налогообложения должен учитывать особенности современных реалий правовой и социальной действительности, а также практических отношений в сфере налогообложения. 
Ключевые слова: налогообложение, налогообложение имущества, налоговая система, налоговая политика, имущество, принципы налогообложения, справедливость налогообложения, механизм.

Цитирование. Казаченков С. Д. Налоговые системы Российской Федерации и США в контексте принципа справедливости налогообложения // Legal Concept = Правовая парадигма. -2021. - Т. 20, № 1. - C. 56-61. DOI: https://doi.org/10.15688/lc.jvolsu.2021.1.8

\section{Введение}

В настоящее время государства разработали более сложные системы и процессы для определения того, кто облагается налогом, что облагается налогом («налоговая база»), сколько облагается налогом и какие личные условия налогоплательщиков должны учитываться. Но что должно лежать в основе справедливого налогообложения, чтобы избежать негативных последствий, и как это повлияет на нашу повседневную жизнь? Любую налоговую систему можно охарактеризовать по следующим критериям: налоговое ведомство, уровень налоговой нагрузки, налоговая ставка, особенности федеративной системы, метод налогообложения и т. д. Практически в любой стране налоговая система настолько сложна, что только профессионально квалифицированные налоговые консультанты / юристы поймут это полностью, и все же от граждан ожидают соблюдения в полном объеме налоговых требований, которые к ним применимы [10]. Справедливым стоит отметить то, что сложность у граждан заключается в определении того, применяются ли налоговые правила [7], и если да, то далее - в технических расчетах, следующих после, чтобы определить, какой размер налога должен быть уплачен и когда [8].

\section{Сравнительный анализ РФ и США в контексте принципа справедливости налогообложения}

Современная налоговая система России была создана к началу XXI в., а система США, напротив, была сформирована в середине XX в. и, таким образом, имеет длительную историю и более слаженный механизм.

Актуальность вопроса состоит в том, что с начала XXI в. и по настоящее время активно проводятся преобразования в налоговой системе по всему миру. В связи с этим представ- ляет интерес рассмотреть в качестве первого критерия особенности налоговой системы двух стран по их федеративному строению - Российской Федерации и Соединенных Штатов Америки, так как они имеют схожее государственное устройство, а также определить сходства и различия и провести сравнительный анализ в целях настоящего исследования для определения того, что соответствует принципу справедливости налогообложения.

Так, в систему налогов и сборов Российской Федерации входят федеральные, региональные и местные налоги и сборы. Налоговая система Соединенных Штатов Америки, аналогично российской, состоит из трех уровней, которые соответствуют трем уровням власти [4, с. 222]:

1) верхний (федеральный уровень) - это федеральные налоги, которые поступают в федеральный бюджет;

2) средний (уровень штатов, аналог региональных налогов) - это налоги и сборы, которые вводятся законами штатов для поступления в бюджет последних;

3) нижний (местный уровень - сюда входят муниципальные образования, графства, округа и иные государственно-территориальные образования) - это налоги, которые вводятся органами местного самоуправления для поступления в местный бюджет.

Однако, кроме очевидных сходств, на практике возникают различия. Так, налоги на уровне штатов в США прямым образом распределяются на программы субъектов Федерации и их освоение. В то же время в РФ разделение налогов строится по определенному принципу, а распределение совершенно иначе: в большей степени процесс сбора происходит вертикально, а затем перераспределяется изза фактора неравенства структуры субъектов нашей страны в виде наличия полезных ископаемых и прочих особенностей.

Второй критерий - налоговое ведомство в структуре налоговой системы. Так, зако- 


\section{ТЕОРИЯ И ПРАКТИКА ГОСУДАРСТВЕННО-ПРАВОВОГО РАЗВИТИЯ}

нодательные органы штатов имеют право вводить налоги, которые бы не противоречили федеральному законодательству США, а органы местного самоуправления в свою очередь вправе взимать налоги, которые разрешены им законами штатов [6]. Структура налоговой системы, во главе которой находится Налоговое управление, или Служба внутренних доходов (Internal Revenue Service), это управление, которое входит в состав Министерства финансов (Department of the Treasury), и одна из наиболее эффективных в мире организаций по управлению в области налогообложения [9]. Налоговое управление, или Служба внутренних доходов (далее СВД), аналогично Федеральной налоговой службе РФ (далее - ФНС РФ) по своим функциям. Служба внутренних доходов США состоит из центрального аппарата, 7 региональных и 58 окружных налоговых управлений, чья деятельность направлена на обеспечение поступления налогов и сборов в бюджет при минимальных задержках. Налоговые проверки классифицируются на камеральные (проводятся по месту нахождения СВД), выездные (проводятся по месту нахождения налогоплательщика) и заочные (проводятся путем направления документов в Контрольное управление СВД по почте) [11]. Региональный уровень представлен налоговыми службами штатов, регулирующими сбор налогов, которые вводятся законодательными собраниями штатов. Последний уровень представляют местные налоговые органы, которые взимают налоги, вводимые органами местного самоуправления. Ставки налогов устанавливаются коллегиально налоговым инспектором, руководителем муниципального органа и председателем совета школ. Следовательно, можно прийти к выводу, что в целом СВД США и ФНС РФ схожи по своим функциям в целом, но различны по своим особенностям.

Современную налоговую систему в Соединенных Штатах Америки характеризуют следующие особенности:

1) прогрессивный характер налогообложения;

2) универсальность обложения - при равенстве сумм дохода обычно действуют однородные налоговые ставки;
3) дискретность налоговых начислений, где каждая более высокая ставка применима лишь к строго определенной части облагаемой суммы;

4) обособленность от налоговых сборов в фонды социального обеспечения;

5) наличие большого количества целевых скидок, льгот и исключений;

6) регулярное изменение действующих ставок налогообложения;

7) фиксированный минимальный уровень индивидуальных доходов, который не подлежит налогообложению [2].

Прогрессивное налогообложение впервые было введено в Великобритании в 1798 году. В России такой режим был установлен царским правительством 6 апреля 1916 г., но из-за революции закон фактически не вступил в действие, а Декретом от 23 ноября 1922 г. налогообложение было реформировано. В СССР шкала подоходного налога всегда была прогрессивной. Так, на доход менее 70 руб. налога не было, от 70 до 90 руб. - $10 \%$, от 90 до 100 руб. - $12 \%$, а 13 \% платили только те, кто получал свыше 100 руб. в месяц. В 1998 г. в России ввели сложную прогрессивную шкалу: доходы до 50 тыс. руб. облагались по ставке $12 \%$, при доходах до 150 тыс. руб. нужно было платить 6 тыс. руб. налогов и $20 \%$ с суммы, превышающей 50 тыс. руб., а с доходов от 150001 руб. налог составлял 26 тыс. руб. и $30 \%$ с суммы сверх 150 тыс. рублей. В 2001 г. у подоходного налога появилось новое название НДФЛ (налог на доходы физических лиц), а в отличие от таких стран, как Великобритания и США, ставка стала единой для всех (плоской) - $13 \%$ [1].

Наконец, переходим к третьему критерию - методу налогообложения. На основе вышеприведенного сравнительного анализа налоговых систем двух стран можно говорить о том, что в нашей стране отсутствует прогрессивное налогообложение и применяется плоская шкала, вследствие чего отсутствует дискретность налоговых начислений. Интересно то, что шкала подоходного налога, который зачисляется в федеральный бюджет США, как уже было выяснено, прогрессивна и, следовательно, основное бремя лежит на обеспеченных 
слоях населения. При этом широко признаны ее «дефекты», так как наблюдается искажение экономической активности, где у владельца высокого дохода остается в собственности сумма меньше, чем у владельца более низкого дохода после уплаты налога, что, по сути, устанавливает сохранение социальной справедливости. Но этот показатель можно считать субъективным, так как, по результатам опроса граждан США (молодых граждан в возрасте 2129 лет, а также их родителей), одни налогоплательщики находят позитивные моменты, другие же ругают справедливость своей системы налогообложения.
И наконец, последний критерий - уровень налоговой нагрузки через особенности размера налоговой ставки. Так, размер ставки подоходного налога в США варьируется в диапазоне от 10 до 37 \%, причем границы ступеней ставки зависят от семейного положения налогоплательщика и растут с каждым годом (табл. 1). В Российской Федерации, напротив, определяются конкретные основания налогообложения, а также отсутствует привязка к налогооблагаемому годовому доходу, не учитывается социальный статус лица, который напрямую влияет на уровень налогообложения (гражданин, находящийся в браке, или родитель-одиночка и т. д.) (табл. 2).

Подоходный налог в США, 2020 г.

\begin{tabular}{|c|c|c|c|}
\hline \multirow{2}{*}{$\begin{array}{c}\text { Налоговая } \\
\text { ставка }\end{array}$} & \multicolumn{3}{|c|}{ Налогоолагаемый годовой доход, долл. } \\
\cline { 2 - 4 } & Физическое лицо & Супружеская пара & Родитель-одиночка \\
\hline $10 \%$ & 0 & 0 & 0 \\
\hline $12 \%$ & 9,875 & 19,750 & 14,100 \\
\hline $22 \%$ & 40,125 & 80,250 & 53,700 \\
\hline $24 \%$ & 85,525 & 171,050 & 85,500 \\
\hline $32 \%$ & 163,300 & 326,600 & 163,300 \\
\hline $35 \%$ & 207,350 & 414,700 & 207,350 \\
\hline $37 \%$ & 518,400 & 622,050 & 518,400 \\
\hline
\end{tabular}

Примечание. Составлено по: [12].

НДФЛ в Российской Федерации, 2020 г.

Таблииа 2

\begin{tabular}{|c|c|c|}
\hline \multirow{2}{*}{$\begin{array}{c}\text { Налоговая } \\
\text { ставка }\end{array}$} & \multicolumn{2}{|r|}{ Категория налогоплательщика } \\
\hline & Резидент & Нерезидент \\
\hline $13 \%$ & $\begin{array}{l}\text { Заработная плата, } \\
\text { вознаграждения по } \\
\text { гражданско-правовым } \\
\text { договорам, доходы от } \\
\text { продажи имущества } \\
\text { (а также некоторые } \\
\text { иные доходы) }\end{array}$ & $\begin{array}{l}\text { 1) осуществление трудовой деятельности (также в качестве высококвали- } \\
\text { фицированного специалиста); } \\
\text { 2) осуществление трудовой деятельности участниками Государственной } \\
\text { программы по оказанию содействия добровольному переселению в РФ со- } \\
\text { отечественников, проживающих за рубежом, а также членами их семей, } \\
\text { совместно переселившимися на постоянное место жительства в РФ; } \\
\text { 3) исполнение трудовых обязанностей членами экипажей судов, плаваю- } \\
\text { щих под государственным флагом РФ }\end{array}$ \\
\hline $15 \%$ & - & Дивиденды, полученные от российских организаций \\
\hline $30 \%$ & - & Все прочие доходы \\
\hline $35 \%$ & $\begin{array}{l}\text { 1) любые выигрыши и } \\
\text { в целях рекламы товар } \\
\text { 2) процентные доходы } \\
\text { 3) сумма экономии на } \\
\text { ния установленных ра } \\
\text { 4) как плата за исполь } \\
\text { ва (пайщиков), а такх } \\
\text { тельским кооперативо } \\
\text { кредитного потребите } \\
\text { кредитного потребите }\end{array}$ & $\begin{array}{l}\text { призы, получаемые в проводимых конкурсах, играх и других мероприятиях } \\
\text { ов, работ и услуг, в части превышения установленных размеров; } \\
\text { по вкладам в банках в части превышения установленных размеров; } \\
\text { процентах при получении заемных (кредитных) средств в части превыше- } \\
\text { змеров; } \\
\text { зование денежных средств членов кредитного потребительского кооперати- } \\
\text { е проценты за использование сельскохозяйственным кредитным потреби- } \\
\text { м средств, привлекаемых в форме займов от членов сельскохозяйственного } \\
\text { льского кооператива или ассоциированных членов сельскохозяйственного } \\
\text { тьского кооператива, в части превышения установленных размеров }\end{array}$ \\
\hline
\end{tabular}

Примечание. Составлено по: [3]. 


\section{Выводы}

Таким образом, говоря о работе механизма принципа справедливости в налогообложении доходов граждан, считаем, что такое налогообложение может осуществляться как по прогрессивной, так и по плоской шкале ставок, несмотря на то что в большинстве стран применяется прогрессивная шкала ставок. В вопросе дискуссионности относительно возвращения к прогрессивной шкале налогообложения для всех граждан необходимо учитывать экономический строй страны и во3можности для верного осуществления принципа справедливости, так как на данный момент плоская шкала налогообложения граждан видится стабильной, а следовательно, справедливой для всех. Тем не менее прогрессивная шкала налогообложения - это отличный вариант работы механизма принципа справедливости для каждого гражданина, но при этом следует учитывать опыт зарубежных стран, а также экономический строй граждан, чтобы, во-первых, данное действие не привело к резкому снижению доходов граждан, а во-вторых, не порождало теневого скрытия доходов при высоких ставках налогообложения, как это бывает в зарубежных странах. Следовательно, в данном вопросе необходимо руководствоваться текущей налоговой и бюджетной политикой государства, экономическим курсом страны, потребностям налогоплательщиков и т. д., тем самым отвечая реалиям современности, ведь, как правильно отметил известный экономист и философ Амартия Сен, «вряд ли стоит всем миром биться над вопросом, почему налог в $39 \%$ справедлив, а налог в 39,5\% - нет (или почему первый "справедливее" последнего) - скоpee, необходимо прийти к действенному соглашению по основным вопросам, не вызывающим сомнений по части справедливости и несправедливости» [5].

\section{СПИСОК ЛИТЕРАТУРЫ}

1. Мелик-Шахназарова, Е. Прогрессивная шкала налогообложения. Как платить подоходный налог в России / Е. Мелик-Шахназарова // Официальный сайт Центральной профсоюзной газе- ты «Солидарность». - Электрон. текстовые дан. Режим доступа: https://www.solidarnost.org/ special/profdict/Vse_o_progressivnoy_shkale_ nalogooblozheniya.html. - Загл. с экрана.

2. Налоговые системы зарубежных стран / В. Ю. Салихова [и др.] // Бухгалтерский учет в издательстве и полиграфии. - 2007. - № 9. - С. 30-35.

3. Налоговый кодекс Российской Федерации (часть вторая) от 05.08.2000 № 117-Ф3 : (ред. от 31.07.2020) // Собрание законодательства РФ. 2000. - № 32. - Ст. 3340.

4. Научный вектор : сб. науч. тр. магистрантов / науч. ред. А. У. Альбеков. - Ростов н/Д : Изд.полигр. комплекс РГЭУ (РИНХ), 2017. - Вып. 3. $244 \mathrm{c}$.

5. Сен, А. Развитие как свобода : пер. с англ. / А. Сен ; под ред. Р. М. Нуреева. М. : Новое изд-во, 2004. $-432 \mathrm{c}$.

6. Ferguson, N. The Ascent of Money: A Financial History of the World / N. Ferguson. - L. : Allen Lane, 2008. - $442 \mathrm{p}$.

7. Frecknall-Hughes, J. The Theory, Principles and Management of Taxation: An Introduction / J. Frecknall-Hughes. - Abingdon : Routledge, 2015. $435 \mathrm{p}$.

8. Hamilton, A. An Enquiry Into the Principles of Taxation, Chiefly Applicable to Articles of Immediate Consumption / A. Hamilton. - Farmington Hills, Michigan : Gale Ecco, 2018. - 452 p.

9. Internal Revenue Service. - Electronic text data. - Mode of access: https://www.irs.gov/uac/theagency-its-mission-and-statutory-authority. - Title from screen.

10. INVESTSA Magazine (November 2014): From the editor. - Electronic text data. - Mode of access: https://issuu.com/cosa/docs/investsa nov issuu/4. Title from screen.

11. Lederman, L. Tax Controversies: Practice and Procedure/ L. Lederman, S. W. Mazza. $-3^{\text {rd }}$ ed. - [S. 1.] : Lexis Nexis, 2008. $-437 \mathrm{p}$.

12. Tax Foundation. - Electronic text data. - Mode of access: https://taxfoundation.org/2020-taxbrackets. - Title from screen.

\section{REFERENCES}

1. Melik-Shakhnazarova E. Progressive scale of taxation. How to pay income tax in Russia. Official website of the Central trade Union newspaper "Solidarity". URL: https://www.solidarnost.org/special/profdict/ Vse_o progressivnoy_shkale_nalogooblozheniya.html.

2. Salikhova V.U., Drozhzhina I.A., Maslov B.G., Zemlyakov U.D., Maslova I.A., Popova L.V. Tax systems of foreign countries. Accounting in publishing and printing, 2007, no. 9, pp. 30-35. 
3. Tax code of the Russian Federation (Part II) of August 05, 2000 no. 117-FZ (ed. from 31.07.2020). Collection of legislation of the Russian Federation, 2000, no. 32, Art. 3340.

4. Albekov A.U., ed. Scientific vector: the collection of scientific works of undergraduates. Rostov n/D, Publishing and printing complex of RSUE, 2017, iss. 3. 244 p.

5. Sen, A. Development as freedom. Moscow, New Publishing House, 2004. 432 p.

6. Ferguson N. The Ascent of Money: A Financial History of the World. London, Allen Lane, 2008. 442 p.

7. Frecknall-Hughes J. The Theory, Principles and Management of Taxation: An Introduction. Abingdon, Routledge, 2015. 435 p.
8. Hamilton A. An Enquiry Into the Principles of Taxation, Chiefly Applicable to Articles of Immediate Consumption. Farmington Hills, Michigan, Gale Ecco, 2018. 452 p.

9. Internal Revenue Service. URL: https:// www.irs.gov/uac/the-agency-its-mission-andstatutory-authority.

10. INVESTSA Magazine (November 2014): From the editor. URL: https://issuu.com/cosa/docs/ investsa_nov_issuu/4.

11. Lederman L., Mazza S.W. Tax Controversies: Practice and Procedure. $3^{\text {rd }}$ ed. Lexis Nexis, 2008. $437 \mathrm{p}$.

12. Tax Foundation. URL: https://taxfoundation. org/2020-tax-brackets.

\section{Information About the Author}

Stanislav D. Kazachenkov, Postgraduate Student, Department of Financial and Administrative Law, Rostov State University of Economics (RINH), B. Sadovaya St, 69, 344002 Rostov-on-Don, Russian Federation, kazachenkov94@mail.ru, https://orcid.org/0000-0002-8090-6800

\section{Информация об авторе}

Станислав Дмитриевич Казаченков, аспирант кафедры финансового и административного права, Ростовский государственный экономический университет (РИНХ), ул. Б. Садовая, 69, 344002 г. Ростов-на-Дону, Российская Федерация, kazachenkov94@mail.ru, https:/orcid.org/0000-0002-8090-6800 